\title{
A VITIVINICULTURA NO ESPAÇO GEOGRÁFICO DO RIO GRANDE DO SUL, BRASIL: UMA ABORDAGEM SOBRE A CAMPANHA GAÚCHA
}

\author{
Vanessa Manfio \\ Universidade Federal do Rio Grande do Sul - UFRGS \\ Núcleo de Estudos Agrários \\ nessamanfio@gmail.com
}

\begin{abstract}
RESUMO
A vitivinicultura é uma atividade antiga no espaço do Rio Grande do Sul, no entanto, somente nas últimas décadas é que mostrou maior dinamismo, a ponto de ser visível a atividade em várias regiões diferentes, empregando mão de obra e tecnologias, além de ser responsável pelo desencadeamento de pesquisas científicas e da criação de culturas e espaços turísticos, marcado de infraestruturas. No Rio Grande do Sul, as duas maiores regiões vitícolas são a Serra Gaúcha e a Campanha Gaúcha, a primeira fortemente estuda, enquanto a segunda merece a atenção, por ser um novo polo de produção de vinhos finos. Por isso, este trabalho objetivou refletir sobre a vitivinicultura gaúcha, seu contexto socioeconômico e espacial, discutindo principalmente a Campanha Gaúcha, as origens e atuais dinâmicas da produção de vinhos. Esperando assim, contribuir com os estudos geográficos referentes à vitivinicultura, que ainda são em número reduzido. Partindo de análises de revisão de literatura, trabalho de campo, leitura da paisagem, coleta de dados e aplicação, numa abordagem qualitativa. Assim, na Campanha Gaúcha, a vitivinicultura que se desenvolve apresenta características modernas e inovadoras, com perspectiva sustentável e ainda articulada por meio de ações coletivas e o vínculo do vinho com a cultura regional.
\end{abstract}

Palavras-chave: Vitivinicultura. Espaço. Rio Grande do Sul. Campanha Gaúcha.

\section{THE VITIVINICULTURE IN THE GEOGRAPHICAL SPACE OF RIO GRANDE DO SUL, BRAZIL: AN APPROACH ABOUT THE CAMPANHA}

\begin{abstract}
Vitiviniculture is an ancient activity in the area of Rio Grande do Sul, however, only in recent decades has it shown greater dynamism, to the point of being visible the activity in several different regions, employing manpower and technologies, besides being responsible by the initiation of scientific research and the creation of cultures and tourist spaces, marked by infrastructures. In Rio Grande do Sul, the two largest winegrowing regions are the Serra Gaúcha and the Campanha of Rio Grande do Sul, the first is strongly studied, while the second is worthy of attention, since it is a new pole of production of fine wines. Therefore, this work aimed to reflect on the viticulture of the state of Rio Grande do Sul, its socioeconomic and spatial context, discussing mainly the Campanha, the origins and current dynamics of wine production. In this way, we hope to contribute to the geographical studies related to viticulture, which are still few in number. Starting from analysis of literature review, field work, landscape reading, data collection and application, in a qualitative approach. Like this the Campanha, the vitiviniculture that develops presents modern and innovative characteristics, with a sustainable perspective and still articulated through collective actions and the linkage of wine with the regional culture.
\end{abstract}

Keywords: Vitiviniculture. Space. Rio Grande do Sul. Campanha of Rio Grande do Sul. 


\section{INTRODUÇÃO}

A vitivinicultura está presente em várias partes do mundo como um elemento de cultura e organização espacial, assim como um sinônimo de economia, desde a antiguidade até a atualidade. Ela é também uma marca da paisagem de diferentes regiões mundiais. Paisagem que Cosgrove (1998, p. 98), conceitua como "uma maneira de compor e harmonizar o mundo externo em uma "cena", em uma unidade visual". Completa ainda o autor que as paisagens se relacionam com a cultura do lugar, com as formas e estruturas visíveis, com a ideia de intervenção humana que modelam o espaço.

No Brasil, as principais paisagens vitícolas estão na Serra Gaúcha, pois a vitivinicultura ganhouespaço nesta região. Embora, a videira apareça no solo brasileiro com a chegada dos "colonizadores" portugueses e espanhóis, que implantaram as primeiras parreiras em áreas de ocupação, foi somente, com os italianos, que trouxeram a cultura e o saber fazer, que a vitivinicultura adquire um viés econômico e cultural. No espaço brasileiro, a vitivinicultura concentrase no Rio Grande do Sul, embora tenha muitas outras regiões investindo na atividade, em virtude das novas possibilidades de mercados e de pesquisas envolvendo os vinhos brasileiros. A Campanha Gaúcha está entre as regiões gaúchas produtoras de vinhos finos. Esta região vem territorializando a vitivinicultura e o enoturismo no seu espaço geográfico.

Diante isso, o presente artigo aborda a trajetória da organização da vitivinicultura na Campanha Gaúcha (RS), tendo como objetivos discutir a inserção da vitivinicultura nesta região, analisando as lógicas e fases dessa inserção territorial, reconhecendo as motivações, os atores, dinâmicas da vitivinicultura no espaço e os desafios a serem superados na territorialização do vinho. Este texto foi construído a partir de análises e também de dados coletados entre 2014-2017 durante a realização da tese de doutorado da autora.

Justifica-se a reflexão a partir da importância que a vitivinicultura apresenta no contexto histórico e econômico do Rio Grande do Sul, bem como na atual organização espacial da Campanha Gaúcha. A vitivinicultura agrega novas condições e formas ao espaço tecendo uma articulação entre cultura, ambiente e vinho, além de alterar a paisagem e as relações socioeconômicas.

Este trabalho teve como recursos metodológicos, a análise do espaço, a revisão de literaturas, os trabalhos de campo, a coleta de dados, as entrevistas semiestruturadas pautada na abordagem qualitativa, dos quais o pesquisador é capaz de interagir com o objeto de pesquisa de forma mais ampla sem necessidade de quantificar dados, mas de entender a dinâmica de estudo. Ainda, utilizou-se o enfoque estruturalista-descritivo para o desenvolvimento do trabalho aqui apresentado. Desse modo, será realizada primeiramente uma reflexão sobre a vitivinicultura no Brasil, suas origens e os novos avanços vitícolas, para, a seguir, abordar a inserção da vitivinicultura na Campanha, suas bases históricas, dinâmicas e atores dentro do processo, e os desafios a serem superados na territorialização do vinho. Espera-se com o trabalho contribuir com as discussões sobre a vitivinicultura da Campanha Gaúcha.

\section{O CONTEXTO DA VITIVINICULTURA NO RIO GRANDE DO SUL: DA HISTÓRIA A ATUALIDADE}

A vitivinicultura no Rio Grande do Sul está vinculada à vinda dos imigrantes na colonização do Estado, primeiramente os alemães e depois os italianos. Segundo Dal Pizzol e Sousa (2014), a colonização alemã desenvolveu a vitivinicultura de quintal, associada à necessidade de plantar uvas e outras plantas para se estabelecerem localmente, no entanto, esta atividade não foi o centro da economia da colônia alemã.

Assim como os portugueses e espanhóis já haviam implantado a videira no Rio Grande do Sul, nas mesmas características de tentativa de fixação da ocupação territorial. Para Sousa (1969) os Padres Jesuítas ao fixar-se na região da fronteira, constituíram os Sete Povos das Missões e plantaram várias espécies de hortaliças, cereais e frutas, inclusive a videira.

Entretanto, com a chegada dos imigrantes italianos, a vitivinicultura no Rio Grande do Sul passa a atingir outra condição, ou seja, passa a ser um elemento de consumo diário e economia local. Assim, Falcade (2011, p. 69) comenta que "a imigração italiana marcou uma nova etapa da evolução da vitivinicultura brasileira". 
O imigrante italiano conseguiu as uvas com os alemães que já estavam assentados na região da Serra Gaúcha (VALDUGA, 2011). Assim, pode perpetuar suas tradições culturais de fabrico e consumo do vinho. Para Manfio (2018, p. 60), "Este imigrante italiano detinha nas suas veias e práticas o hábito de cultivar e produzir o vinho, com isto quando se estabeleceu na nova terra passou a buscar condições para realização da elaboração do vinho". Sabe-se que "O fabrico, no início da colonização era feito artesanalmente pelos imigrantes e as cantinas estavam localizadas nos porões das casas" (SALAMONI; DUARTE, 2011, p.212).

Aos poucos este produto foi comercializado localmente. Segundo Santos (1978) o vinho era produzido pelo camponês italiano na forma de um artesanato doméstico: após a colheita da uva, a família fabricava o vinho na cantina, compartimento de pedra situado geralmente na parte de baixo da casa, onde ficavam as pipas de madeira e os instrumentos de fabricação do vinho. Terminado o ciclo de elaboração da bebida, este era vendido aos comerciantes locais que realizavam as transações comerciais (SANTOS, 1978).

Logo, o comércio local foi insuficiente para escoar a produção de vinhos. Segundo Ortega e Jeziorny (2011, p.32),

Foi no início do século XX que a produção de vinho gaúcho começou a se tornar demasiadamente grande para o mercado regional. Neste momento, quanto à oferta de vinho se tornou excedente para o mercado local, organizou-se a primeira investida em outros mercados, e a partir desse momento, o vinho gaúcho começou a desembarcar em São Paulo e, posteriormente, em outros estados.

Neste momento, o Estado também passa atuar na vitivinicultura gaúcha, pois era necessária certa qualidade ao vinho. O governo do Estado do Rio Grande do Sul instituiu a Estação Agronômica e passou a importar mudas de videiras, repassando aos colonos, além de trazer enólogos italianos para difundir técnicas de vinificação e cultivo da uva (ORTEGA; JEZIORNY, 2011).

O governo incentivou também a industrialização do vinho através da criação de instituições de ensino e de pesquisa, onde foi possível ministrar cursos para viticultores (REAL, 1981). A criação de legislações sanitárias foi importante no avanço da vitivinicultura como uma nova atividade comercial. Em Falcade (2011), consta que por volta de 1930 houve mudanças no espaço geográfico, especialmente da Serra Gaúcha, devido às legislações sanitárias que dificultaram a produção artesanal do vinho e centralizaram a vinificação nas grandes vinícolas.

Nesse sentido, Falcade (2011, p. 80) diz que "outro fator fundamental foi à criação da Sociedade Vinícola Rio-Grandense Ltda, conhecida como Sindicato do Vinho". Esta associação definiu normas para elaboração, conservação e comercialização do vinho (FALCADE, 2011). Este sindicato contribuiu para que os produtores artesanais tivessem dificuldade em comercializar seus vinhos em virtude as regras. Conforme Nierderle (2011, p.58), "Frente ao poder do Sindicato e às exigências legais e sanitárias cada vez mais rigorosas, as quais praticamente impossibilitavam a produção artesanal, os agricultores investiram na organização cooperativada". Ressalta Manfio (2018, p.62-63), "A reação dos pequenos produtores de vinhos locais, desprivilegiados com a criação do Sindicato do Vinho, levou ao aparecimento de cooperativas vinícolas que repercutiram no aumento da competição vitícola gaúcha" (MANFIO, 2018, p.62-63). No entanto, apenas a partir de 1930 surgiram cooperativas vitícolas com força para enfrentar o poder econômico das vinícolas privadas, sendo as primeiras cooperativas a surgir a Cooperativa de Garibaldi (1931) e a Cooperativa vinícola Aurora de Bento Gonçalves em 1933 (NIERDERLE, 2011).

Convém destacar que nas décadas de 1960 e 1970 houve a introdução de tecnologia de ponta, a atuação de enólogos, formados em vários países, e a chegada das multinacionais como: Martini \& Rossi, Heublein, Cinzano e Almadén (Mello, 2007). Quanto à introdução de tecnologias e novas cepagens de videiras, Jalfim e Grando (1990, p. 205) colocam que,

A viabilidade desse processo foi dada, de um lado, pela existência de um mercado interno economicamente apto ao consumo de vinhos de maior qualidade e pela presença de um setor empresarial regional capaz de absorver as mudanças tecnológicas necessárias para a reorganização da produção vinícola. Por outro, esse processo também só foi possível pelas transformações ocorridas no setor agrícola a partir da mudança na composição dos parreirais, configurada na adoção de videiras de viníferas, o que exigiu do vinicultora absorção de inovações tecnológicas. 
Nesta época, a necessidade de expansão da vitivinicultura para além da Serra Gaúcha, devido ao alto preço da terra nesta região e a indisponibilidade de terrenos fizeram com que empresas apostassem em outras áreas para implantação de vinhedos e unidades empresariais. Empresas, tais como: a Salton, a Miolo, Valduga, entre outras adquiriam terras na Campanha Gaúcha, Campos de Cima e Serra de Sudeste (Figura 1). Havia a necessidade ainda de aumentar a possibilidade de produzir vinhos finos de qualidade e com outras tipicidades de uvas, modernizando a produção de vinhos no Brasil.

Convém destacar que a moderna produção de vinhos finos, não está centrada apenas no RS, ela se estendeu para outras regiões brasileiras. No sul do Brasil o Planalto Catarinense também está entre as áreas importantes de vitivinicultura.

Figura 1 - Localização das principais regiões vitícolas do sul do Brasil.

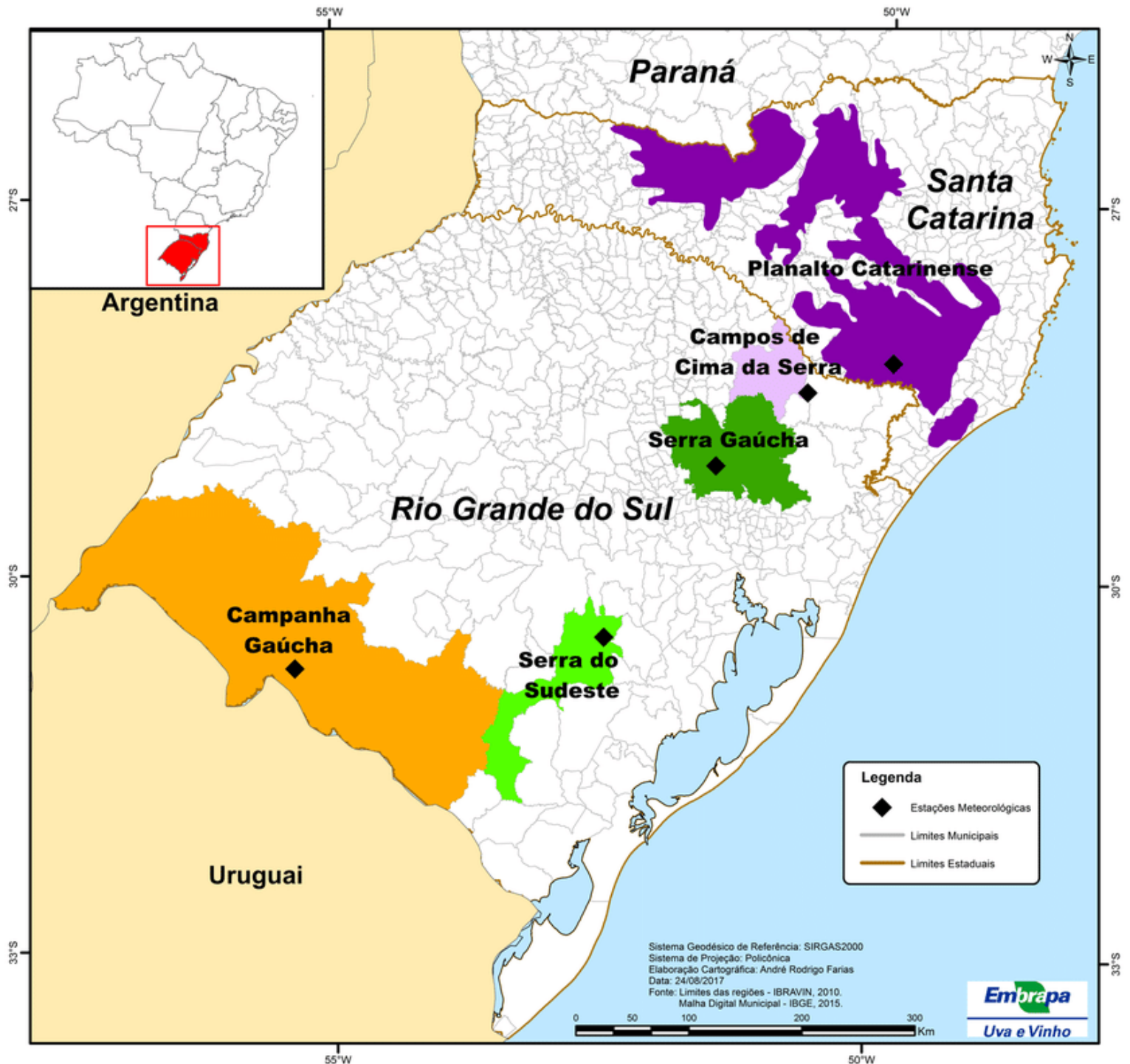

Fonte - ALVES, M. E. B. TONIETTO, J. Condições meterológicas e sua influência na safra vitícola de 2017 em regiões produtoras de vinhos finos do Sul do Brasil. Comunicado técnico 201. Bento Gonçalves: EMBRAPA uva e vinho, set. 2017.

Na Serra Gaúcha, "a vitivinicultura se tornou a principal atividade econômica da região, a paisagem dos vinhedos se consagrou como a grande "marca" do lugar, é um símbolo identitário da região, caracteriza e representa o viticultor, descendente de imigrantes italianos" (PIEROZAN; MANFIO; MEDEIROS, 2017, p. 4719). 
As regiões Campanha Gaúcha, Serra de Sudeste e Campos de Cima estão sendo incorporada no segmento dos vinhos e contem a atuação de empresas da Serra Gaúcha e de produtores locais, numa vitivinicultura moderna.

Claro que existem outras áreas gaúchas que estão se organizando na produção de uvas e vinhos artesanais, como a região de descendência italiana da região da Quarta Colônia, Santa Maria (centro do estado gaúcho), Pelotas (sul do estado, antigas colônias italianas: Maciel e São Manoel) e a região das Missões Jesuíticas (Oeste do Rio Grande do Sul). Portanto, vem se criando novos polos produtores de uva e vinho no Rio Grande do Sul e no Brasil.

$\mathrm{Na}$ Quarta Colônia a vitivinicultura é de caráter artesanal e pontual, com vinhedos centenários e com novos vinhedos pouco modernos. A produção de vinhos vem sendo investida na região por pequenas cantinas que estão se articulando para a comercialização do vinho, tais quais: vinícola Óperaviva (Recanto do Maestro - Restinga Seca).

Em Pelotas, a fabricação do vinho também é em moldes artesanais com a utilização de métodos de fabricação considerados naturais e identitários da cultura italiana, que colonizou a região (SALAMONI; DUARTE, 2011).

Ademais, Santa Maria e Itaara tem se destacado com a presença de vinícolas, como Vinícola Velho Amancio, Vinícola Dalla Corte, República do Vinho, influenciadas pela visibilidade que a vitivinicultura atingiu nos últimos anos e pela descendência italiana que migrou para estas duas cidades.

Nas Missões a vitivinicultura também é artesanal e pontual, é uma região onde os Padres Jesuítas implantaram a videira e hoje existem produtores investindo em vinho, principalmente em São Borja e São Luiz Gonzaga. Estes produtores estão pautados na história do vinho na região e na possibilidade de desenvolvimento que a atividade representa espacialmente.

Diante da evolução da vitivinicultura, o enoturismo vem sendo incentivado para alavancar a indústria do vinho. "Os investimentos no segmento enoturístico contemplam atualização de pesquisas visando à identificação, configuração e inovação dos atrativos locais e à formatação de roteiros e estratégias de marketing" (SALVAGNI; VALDUGA; NODARI, 2016, p.255). Assim, indústrias vinícolas, empresários, poder público e camponeses, através do turismo, estão se aproveitando do capital simbólico e das paisagens agrárias para ampliar a visibilidade dos vinhos e aumentar a renda econômica, implicando também nas transformações substanciais do espaço geográfico onde se desenvolve a vitivinicultura (SILVA, 2009).

Ainda, a entrada de vinhos estrangeiros levou a vitivinicultura gaúcha a tomar medidas de desenvolvimento, e valorização dos vinhos gaúchos através da busca por Indicações Geográficas (IGs). Segundo Nierderle e Aguiar (2012, p. 23),

[...] as IGs revelaram-se a expressão máxima de um estilo de produção assentado na valorização dos territórios e em métodos tradicionais de viticultura e vinificação, constituindo um contraponto a um modelo industrial de vitivinicultura que procurava superar os limites impostos pela natureza a partir da padronização das técnicas de produção.

Neste caso, à conquista da Indicação de Procedência e Denominação de Origem, ambas conquistadas pelo Vale dos Vinhedos promoveram uma organização produtiva de algumas vinícolas em meados dos anos 1990, tendo como resultado também a criação da Associação dos Produtores de Vinhos Finos do Vale dos Vinhedos - APROVALE (SALVAGNI; VALDUGA; NODARI, 2016). Para Nierderle e Aguiar (2012, p. 28) "a APROVALE tornou-se um dos atores mais importantes no território". A partir desta iniciativa outras regiões vitícolas iniciaram o mesmo processo de organização produtiva para Indicação Geográfica, entre elas a Campanha Gaúcha.

Nesta condição verifica-se "uma nova fase da vitivinicultura nacional, marcada pela busca da consagração das características territoriais do vinho. Atravessa-se, portanto, na vitivinicultura brasileira, uma nova fase, a das indicações geográficas" (ORTEGA; JEZIORNY, 2011, p 61).

Por tudo que foi exposto, a vitivinicultura no Brasil apresenta quatro fases ou períodos históricos como menciona Tonietto (2003): o primeiro de implantação da vitivinicultura na Serra Gaúcha, no período do século XIX até 1920; o segundo data de 1930 a 1960 onde ocorre a diversificação dos 
produtos vitícolas e melhoria dos vinhos; enquanto o terceiro de 1970 a 1990 está marcado pelo cultivo de videiras vitis viníferas e produção de vinhos finos; e por último, após 2000 até hoje o período de certificações e identidade dos vinhos.

Atualmente, a vitivinicultura do Rio Grande do Sul encontra-se concentrada na Serra Gaúcha e na Campanha Gaúcha, expandindo-se lentamente para outras áreas. Na Serra ainda existe uma vitivinicultura tradicional que aos poucos vai sendo substituída pela inserção de vinhedos em espaldeira e técnicas modernas. Enquanto isso na Campanha a vitivinicultura é moderna, empregase tecnologia e pesquisa para o sucesso da produção, videiras em espaldeira e mecanização. Entre outros fatores, o sucesso vitícola destas regiões faz com que o Rio Grande do Sul seja, ainda nos dias de hoje, o maior produtor de vinhos do cenário brasileiro. Conforme Farias (2011, p. 57), "Cerca de $90 \%$ da produção nacional de vinhos está concentrada no Rio Grande do Sul, notadamente na Serra Gaúcha". Ainda, sobre o assunto Mattei e Triches (2009, p. 162) discutem que,

O cenário atual da vitivinicultura gaúcha permite constatar que a atividade permanece como uma das mais importantes para a economia do estado riograndense, principalmente quando se observa o número de pessoas empregadas na cadeia, o valor dos impostos gerados, as exportações realizadas e as ações correlatas proporcionadas por esta atividade produtiva.

Portanto, o Rio Grande do Sul apresenta um espaço consolidado e também organizado produtivamente com a vitivinicultura. Esta se associa à história gaúcha e também as novas dinâmicas da produção de vinhos vinculadas, principalmente aos vinhos finos e agroecológicos.

\section{A VITIVINICULTURA NA CAMPANHA GAÚCHA: A PRODUÇÃO DE VINHOS FINOS NOS PAMPAS}

A produção de uvas na Campanha Gaúcha começa a se desenhar na época da colonização portuguesa no Brasil, mas ganha importância apenas recentemente. Conforme Oliveira, Martinez e Santos (2015, p. 120),

A produção de uvas na região em estudo teve início em áreas precisas com os jesuítas no século XVII e com os portugueses no século XVIII, mas não configurou identidade do território que cobrisse sua continuação, pois na época não foram intensamente trabalhadas e incentivadas e, devido a isso, não tiveram prolongamento.

Os estudos promovidos pelo Estado gaúcho em parceria com instituições e pesquisadores apontaram a descoberta de novas áreas com condições edafoclimáticas adequadas para 0 desenvolvimento da vitivinicultura (MANFIO; MEDEIROS; FONTOURA, 2016).

Além das condições da região, a necessidade de expansão da produção de vinhos que não encontrava mais terras baratas e disponíveis na Serra Gaúcha levou o deslocamento da produção para Campanha Gaúcha. A tentativa de diversificação da economia da Campanha, marcada pelo latifúndio, pecuária e agricultura, que não atingia o desenvolvimento social e econômico igualitário na região trouxe o incentivo para o desenvolvimento da fruticultura, vitivinicultura, silvicultura, entre outras atividades.

Estes motivos culminaram no pontapé para a inserção de empresas da Serra Gaúcha na fronteira para produzir vinhos finos. De acordo com Flores e Medeiros (2013, p. 7),

Os pioneiros da vitivinicultura na região foram do grupo da Vitivinicultura Corporativa, que se destaca por extensas áreas de cultivos. Atualmente, a totalidade dos componentes deste grupo é formada por empresas pertencentes as vinícolas da Serra Gaúcha. A presença da Serra na Campanha se dá motivada por uma expansão de áreas das vinícolas locais, atraídas pelos preços mais baixos das terras aliado a condições de produção propícias. Nos primeiros casos, ocorreu aquisição de vinícolas, nas expansões mais recentes as vinícolas iniciam implantação de novos projetos. 
A partir deste momento, ocorrem à entrada de empresários da região da Campanha, pecuaristas na maioria, e de pessoas bem-sucedidas de outros lugares. Como afirmam Flores e Medeiros (2013, p. 3), "a partir do ano 2000, novos atores se apresentam e começa a ocorrer à nacionalização dos investimentos e um movimento de expansão de vinícolas tradicionais da Serra Gaúcha para a região da Campanha".

Ademais, "surgiram vinícolas novas na Campanha Gaúcha que passam a investir na qualidade do produto. Mais recentemente cresce o entendimento da necessidade de diferenciação e de agregação de valor ao produto através da elaboração de selos de qualidade" (SILVA; ANJOS; SILVEIRA, 2018, p.188). Isto se deve principalmente a busca por uma Indicação de Procedência (IP) para os vinhos da Campanha que valorize o produto e associe a região aos vinhos.

A partir de 2010, outros empresários passam a aglutinar-se na territorialização do vinho da Campanha, tal qual: a Vinhetica. Assim como, empresas têm alterado sua participação na Cadeia do Vinho, como a Vinícola Rio Velho e Irmãos Camponogara. Os irmãos Camponogara continuam desenvolvendo a produção de vinhos, no entanto estão investindo em vinhos artesanais para atender o mercado local, assim os gastos têm sido menores em relação à colocação da empresa no mercado dos vinhos finos (MANFIO, 2018).

Dessa forma, a gênese contemporânea da vitivinicultura na Campanha Gaúcha pode ser vista por momentos distintos. Conforme Flores (2011), a primeira fase da vitivinicultura da Campanha ocorre na década de 1970, caracterizando-se por estudos edafoclimáticos e instalação de vinhedos de empresas da Serra Gaúcha; segunda fase é a evolução e expansão da vitivinicultura; terceira fase compõem o surgimento de novos investidores e empreendedores do vinho e a consolidação da IG. A entrada de novos investidores na Campanha permitiu também a organização da região num espaço de vitivinicultura marcado por vários municípios com propriedades de produção de uva e vinho. Destacam-se os municípios Alegrete, Bagé, Candiota, Dom Pedrito, Itaqui, Hulha Negra, Quaraí, Maçambara, Rosário do Sul, Santana do Livramento e Uruguaiana (figura 2).

Figura 2 - Mapa de localização da área vitícola da Campanha Gaúcha.
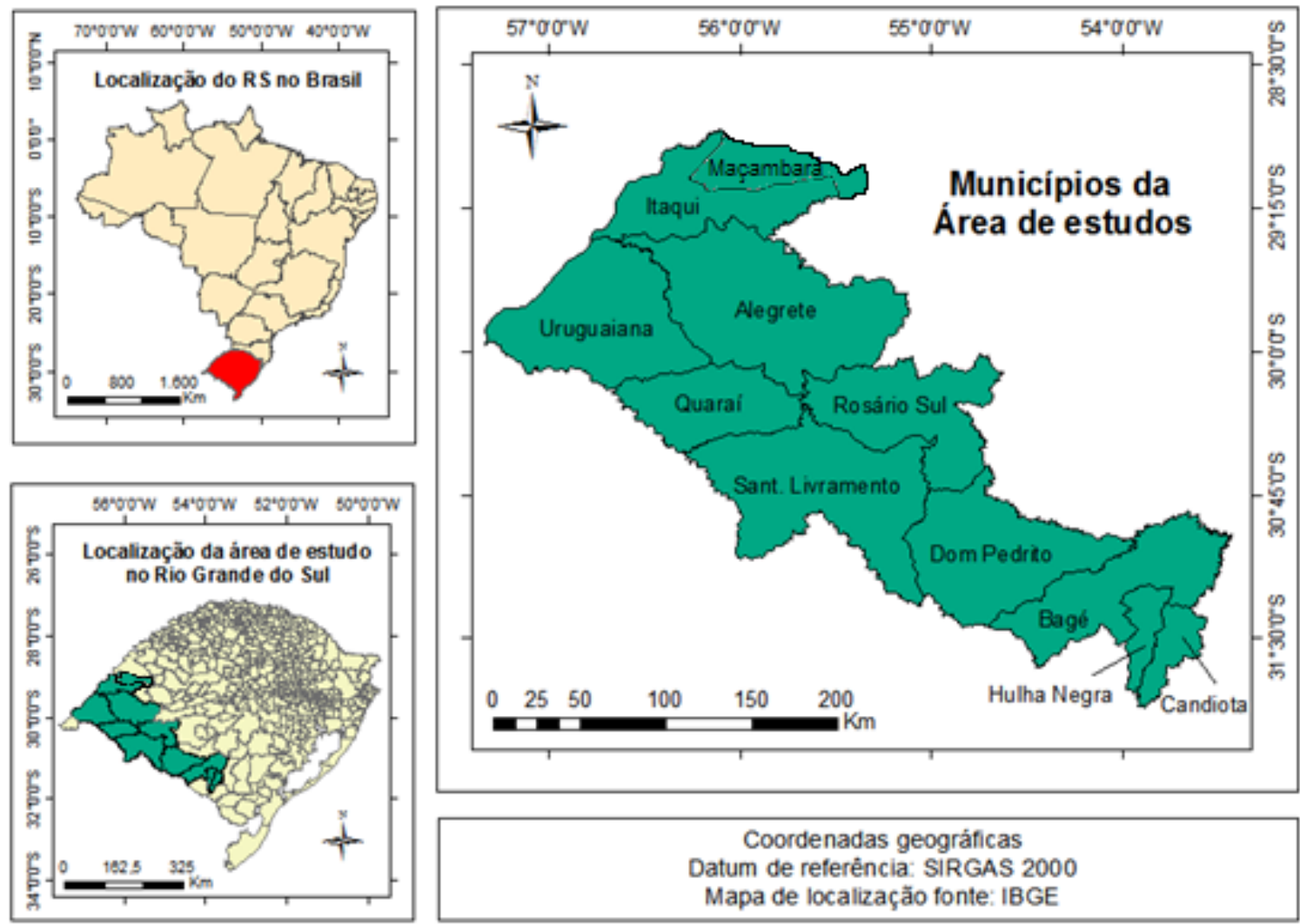

Fonte - IBGE, organizado pela autora (2017). 
Mediante aos diferentes momentos da evolução da vitivinicultura Campanha surgem diferentes atores espaciais que disputam o território do vinho tais como: a) grandes empresas vindas da Serra Gaúcha (Salton, Almadén, Miolo, Cooperativa Nova Aliança); b) empresas pequenas estilo boutique (produção em menor escala, mais eletizada), tal qual a Guatambu - Estância do Vinho, a Dunamis, a Campos de Cima, a Cordilheira Santana, a Vinhética, a Estância Paraízo, a Peruzzo Vinhas e Vinhos, entre outras; c) produtores de uva e vinhos orgânicos, como a Família Marin de Dom Pedrito; d) produtores de vinhos artesanais, que estão vinculados ao mercado local, por exemplo, Irmãos Camponogara e a Família Costa de Dom Pedrito; e) os produtores de uvas para as empresas da região já consolidadas, como os produtores de uva de Santana do Livramento.

Com estes diferentes grupos e a recente organização da vitivinicultura na Campanha há a necessidade da iniciativa de ações coletivas para permitir o avanço da produção de vinhos, a superação de dificuldades e a busca por um reconhecimento econômico. Estas ações coletivas são realçadas com a criação da Associação dos Produtores de Vinhos Finos da Campanha Gaúcha (Associação Vinhos da Campanha). Esta associação, "tem sido um facilitador para aquisição de políticas públicas voltadas à atividade, além da construção de subsídios para o reconhecimento da Identificação Geográfica (IG) e para o desenvolvimento do enoturismo" (MANFIO; MEDEIROS, 2017, p. 145).

A Indicação de Procedência dos Vinhos e Espumante da Campanha Gaúcha já foi protocolada no Instituto Nacional da Propriedade Industrial (INPI) e aguarda aprovação. Foi um estudo promovido pela Associação Vinhos da Campanha e esta mesma entidade será a gestora da IP, caso aprovada.

$\mathrm{Na}$ Associação Vinhos da Campanha apenas participam as empresas da Serra Gaúcha e os empresários de vinhos finos que atuam na região, pois os demais atores não se enquadram nas filosofias e estratégias de desenvolvimento local, ou seja, a busca de uma Indicação Geográfica e o marketing, enoturismo, para os produtores de vinhos artesanais e de uva não são os principais objetivos dos seus investimentos. Estes produtores de uva e vinho artesanal não têm capitais para investirem nas infraestruturas aspiradas pelos grandes empresários. Logo, Manfio e Medeiros (2016, p. 9) dizem que, "ocorre uma separação entre a agroindústria artesanal e as vinícolas comerciais, com uma centralização do capital nas mãos dos grandes comerciantes do vinho".

Esta separação faz surgir no espaço da Campanha outras associações formadas por outros grupos de viticultores da região como a Associação Santanense de Produtores de Uva (ASPROUVA) e a Associação Quaraiense de Fruticultures (Aquafrut).

As estratégias das associações presentes na Campanha Gaúcha é desenvolver o setor de vinhos e de produção de uva, criando condições para o enoturismo, o comércio e as iniciativas de marketing e reconhecimento da região como produtora de uvas e vinhos de qualidade.

Ao falar dos vinhos de qualidade, estes são produzidos a partir de castas de videira principalmente de "Tannat, Sauvignon Blanc, Chardonnay, Pinot Noir, Merlot, Cabernet Sauvignon, entre outras, que são destinadas a produção de vinhos e espumantes" (MANFIO; MEDEIROS, 2017, p.150). Assim, todas as videiras são de "vitis-vinífera" e plantadas no sistema de espaldeira que permitem melhor qualidade ao vinho (ASSOCIAÇÃO VINHOS DA CAMPANHA, 2018).

O sistema de espaldeira também permite a mecanização, e como a Campanha está inserida no domínio do Bioma Pampa apresenta características de campos de gramíneas e de relevo suave a ondulado, condições que permite a inserção de tecnologias e maquinários modernos. Além disso, os invernos rigorosos e forte insolação, por sua vez favorecem a maturação e qualidade da uva.

Mesmo na vitivinicultura de produtores de vinhos artesanais são utilizadas as videiras vitís viníferas e videiras em espaldeira. Apenas para as uvas comerciadas in natura para o consumo é que apresenta parreirais no sistema de mesa (Trabalho de campo, 2017). A Vinícola Peruzzo apresenta um espaço de uvas de mesa para o comércio nas redes de supermercados da família (trabalho de campo, 2016).

Alguns produtores de vinhos artesanais e de uva de Dom Pedrito, desenvolvem a produção orgânica. Estes produtores "de uva orgânica de Dom Pedrito fazem parte da agricultura familiar e buscam sempre diversificar sua produção agrícola, pois não produzem apenas uvas, eles também cultivam hortaliças, flores, oliveiras, etc." (PIEROZAN; MANFIO; MEDEIROS, 2018, p. 
2628). Eles estão inseridos em várias políticas públicas, como o Programa de Desenvolvimento da Fruticultura Irrigada na Metade Sul/RS que tem como finalidade o desenvolvimento da fruticultura na região da Campanha Gaúcha.

Retornando a modernização da produção do vinho na região, esta de maneira geral, desenvolvese, de forma tecnológica e moderna. Segundo Manfio (2018), na Campanha há expressiva incrementação da modernização vitivinícola, que variam desde tratores, tesouras elétricas, até recentemente colheitadeiras de uvas.

Ainda, "A modernização dos vinhedos também é percebida no espaço territorial da Campanha Gaúcha pelas instalações de grandes extensões de vinhedos homogêneos e pela concentração de empresas e empresários com poder aquisitivo para o investimento vitícola" (MANFIO, 2018, p. 171). Neste sentido, observa-se a presença de grandes propriedades de uvas (figura 3 ) relacionadas às empresas: Salton com uma área em torno de 120 hectares, Almadén (Grupo Miolo) com 450 hectares, e a Seival Estate (Miolo) com 200 hectares (MANFIO, 2018). Sobre a empresa Salton, aos poucos ela pretende implantar vinhedos, nos 450 hectares da propriedade que tem na Campanha Gaúcha (ZERO HORA, 2017), ampliando a produção de uvas e vinhos. Já as empresas da Campanha apresentam de 5 a 20 hectares de vinhedos e algumas apenas têm propriedade de vinho, sem espaço para vinificação, ou seja, sem vinícola.

Estas empresas juntas vêm alterando a paisagem e o espaço da Campanha Gaúcha, que se evidencia pela presença de extensões de vinhos, lojas e vinícolas, desenvolvimento do enoturismo com rotas e estabelecimentos comerciais fazendo parte do movimento vitícola e do emprego de trabalhadores nos vinhedos e vinícolas. Isto representa uma mudança de diversificação produtiva.

Figura 3 - Tecnologia nos vinhedos na Campanha Gaúcha.

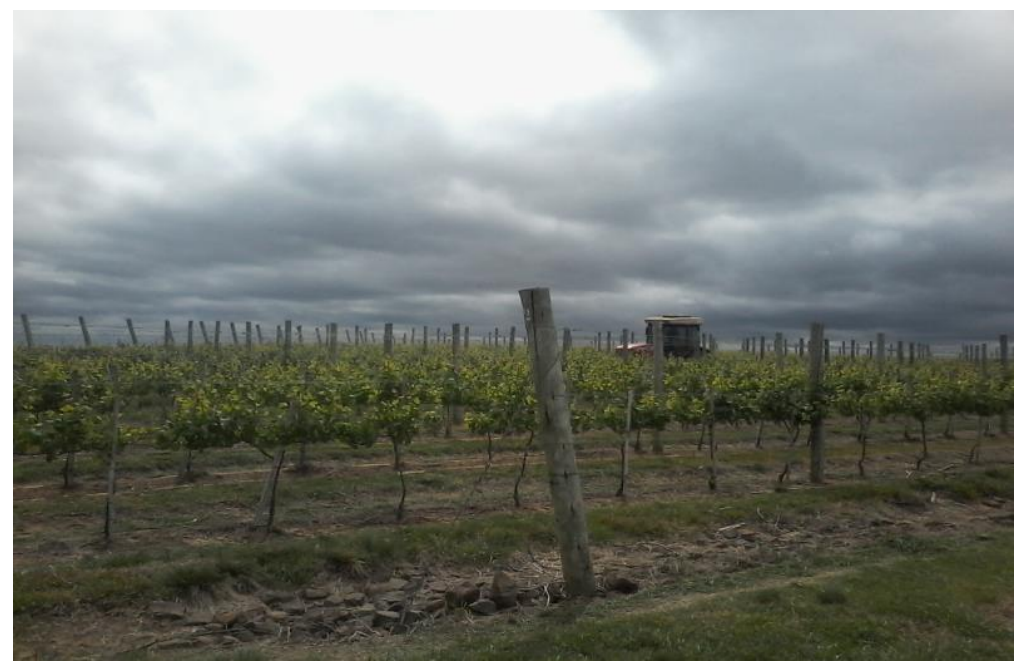

Fonte - acervo do autor (foto tirada em setembro de 2016).

As empresas têm empregado contingente de pessoas para serviços terciários de colheita e poda nos vinhedos. Além disso, as empresas vinícolas têm contratado enólogos e agrônomos para a elaboração do vinho e tratamento dos vinhedos. Em geral, são entorno de 5 pessoas fixas em cada propriedade vitícola.

A produção de vinhos tem trazido também a instalação de cursos de formação profissional na região, tais quais, destacam-se o Curso de Bacharelado em Enologia, no Campus da UNIPAMPA, em Dom Pedrito e o Curso Superior de Tecnologia em Viticultura e Enologia do Instituto Federal de Educação, Ciência e Tecnologia Sul-rio-grandense do Campus Pelotas (IFSUL-Pelotas).

Essa mudança produtiva e tecnologia utilizada coloca a região da Campanha como uma área de expressiva dinâmica vitícola. Segundo o quadro 1 , que considera os municípios de maior participação na vitivinicultura na Campanha é possível notar que Santana do Livramento apresenta uma grande extensão de vinhedos ( 965,79 ha) e elevada produção de uva $(5628,10$ to), distribuídas em 33 propriedades rurais, assim como os demais municípios apresentam menor intensidade na produção, mas significativa. 
Quadro 1 - Dados de área e produção de uvas nos principais municípios produtores de uva da Campanha Gaúcha.

\begin{tabular}{|l|l|l|l|}
\hline Municípios & $\begin{array}{l}\text { № de } \\
\text { propriedades }\end{array}$ & Área (ha) & $\begin{array}{l}\text { Produção } \\
\text { (ton.) }\end{array}$ \\
\hline Bagé & 14 & 105,32 & 299,05 \\
\hline Candiota & 4 & 218,73 & 1211,06 \\
\hline Dom Pedrito & 7 & 94,49 & 491,53 \\
\hline Quaraí & 14 & 64,12 & 439,15 \\
\hline $\begin{array}{l}\text { Santana do } \\
\text { Livramento }\end{array}$ & 33 & 965,79 & 5628,10 \\
\hline
\end{tabular}

Fonte - (MELLO; MACHADO, 2017)

Claro que além da área tem-se que levar em consideração os aspectos naturais de cada município, como é o caso de Quaraí que numa área menor, produz mais toneladas de uva, em relação a Bagé, por exemplo.

Se levarmos em consideração todas as propriedades e a produção de vinhos, tem-se uma nova resposta a mudança qualitativa das atividades desenvolvidas na região. Assim, aos poucos a vitivinicultura vai se territorializando na região e alterando as antigas bases trabalhistas, econômicas e sociais.

É importante frisar que a concentração de propriedades de vinhedos na Campanha Gaúcha está nos municípios de Santana do Livramento, Bagé, Quaraí e Dom Pedrito (MELLO; MACHADO, 2017). Nestas áreas também é aonde o enoturismo vem se consolidando, com a criação de rotas enoturísticas e atividades turísticas pontuais, juntamente com a constituição de cantinas e vinícolas importantes, tais quais: a Almadén (Grupo Miolo), Salton, Cordilheira Santana, Guatambu Estância do Vinho, Peruzzo Vinhas \& Vinhos.

Além da modernização, chama-se atenção na Campanha Gaúcha à inserção do vinho a cultura local, ou seja, a cultura tradicionalista gaúcha, fugindo da ideia de vinho e imigrante italiano que é fortemente vinculada ao vinho gaúcho e brasileiro. Desse modo, Flores (2017, p. 131) expõe que

\begin{abstract}
[...] na Campanha Gaúcha, é possível observar o vínculo dos vinhos com o "gaúcho" e com elementos da cultura local, tais como o bioma pampa, pecuária (ovina e bovina), cavalos, o vento "minuano", o relevo do pampa e os cerros. Tais elementos aparecem no discurso dos atores, assim como no material de comunicação das vinícolas, em forma de fotografia, iconografia ou elementos de linguagem. Há, também, elementos históricos ou relacionados ao bioma pampa que aparecem no nome dos vinhos e nos rótulos.
\end{abstract}

Esta articulação do vinho e a cultura vem sendo criada pelos atores territoriais e estão materializados na paisagem. Segundo Manfio (2018, p. 200), "A paisagem vitícola que se desenha na Campanha acompanha as relações sociedade-natureza e história que existe na região". O vinho acaba por alterar a paisagem, onde via-se vastos campos, agora vê-se vinhedos e vinícolas. No entanto, a vitivinicultura que se desenvolve, principalmente por empresas vitícolas constituída na Campanha, vem tentando articular as memórias históricas, a cultura e o ambiente. Estes elementos são visíveis nos nomes dos vinhos, (Lendas do Pampa, Vinho da Estância, Vinho Angus da Guatambu Estância do Vinho, por exemplo), no nome das vinícolas (Guatambu Estância do Vinho, Batalha Vinhas \& Vinhos e Estância Paraizo) na arquitetura e gastronomia que envolve a vitivinicultura, nas rotas enoturísticas que estão sendo constituída na região (como é o caso da rota Ferradura dos Vinhedos de Santana do Livramento) e no próprio marketing das vinícolas.

Claro que as empresas da Serra Gaúcha não demonstram a mesma importância com a preservação da identidade regional, mas acabam participando do marketing e enoturismo proposto pela Associação Vinhos da Campanha, que tem como objetivos promover uma vitivinicultura associando região e vinho. 
Quanto a rota Ferradura dos Vinhedos, abordada acima, esta apresenta um formato de ferradura de cavalo e abrange passeios nas vinícolas de Santana do Livramento, nos pontos históricos e naturais da cidade e termina com almoço no (Centro de Tradições Gaúchas (CTG) do município.

Esta identificação permite uma diferenciação nos vinhos e nas atividades enoturísticas. É uma marca única da região. A presença da pecuária, dos cavalos, da estância, do Bioma Pampa, da história e cultura gaúcha é essencial no território. Estes elementos são um ponto de intersecção entre espaço, cultura e vinho. A figura 4 reforça o laço da cultura gaúcha (identidade cultural da Campanha) nas vinícolas, onde é possível visualizar nas portas dos banheiros da vinícola Guatambu - Estância do Vinho a representação do peão (banheiro masculino) e prenda (banheiro feminino). O peão e a prenda são figuras do tradicionalismo gaúcho.

A sustentabilidade também é uma iniciativa presente no espaço vitícola da Campanha Gaúcha através, especialmente da inserção de painéis solares, redução do número de agrotóxicos e de embalagens biodegradáveis, ou ainda pela produção de vinhos e sucos orgânicos.

Diante disso, existe uma transformação no espaço regional vista através da inserção de vinhedos, vinícolas e cantinas, espaços enoturísticos, banners, entre outros elementos. Esta transformação se dá ainda pela articulação do segmento de hotéis e restaurante com as empresas vitícolas, a organização do território do vinho e da economia.

Figura 4 - Elementos da cultura gaúcha, o peão e a prenda na vinícola.

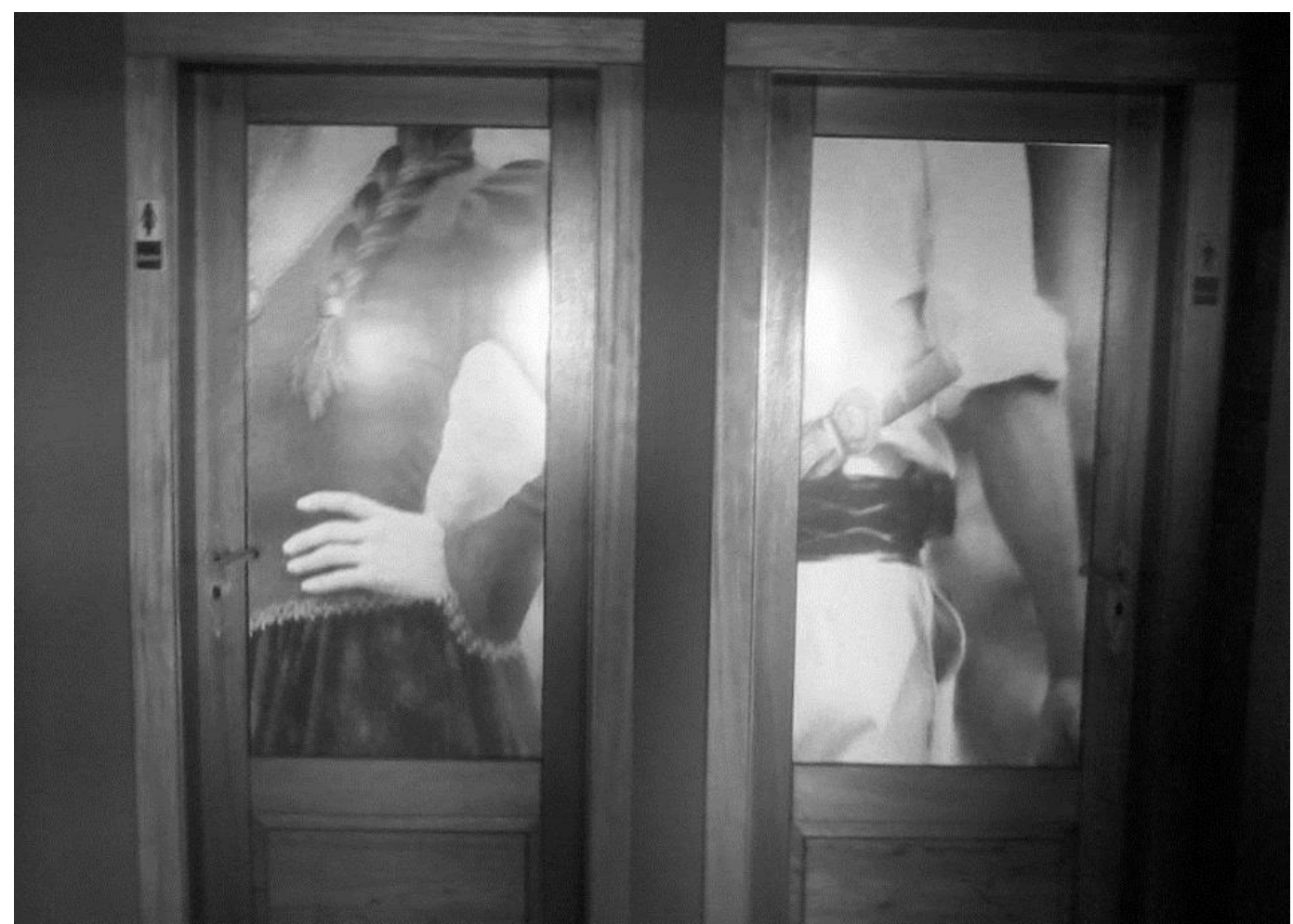

Fonte - acervo do autor (foto tirada em setembro de 2015).

Diante do exposto, a Campanha vem se inserindo na cadeia produtiva do vinho, apresentando atores diferentes, produtores de vinhos finos da Serra Gaúcha e da própria região, produtores de uva, produtores de vinhos artesanais, produtores de vinhos e sucos orgânicos. Cada um destes atores disputa seu lugar no território do vinho através de suas articulações e dinâmicas. Conforme Manfio e Medeiros (2016), mesmo existindo um monopólio do vinho centrado em grandes empresários, esta condição ainda não tem sido foco de resistências e lutas, pois cada grupo de produtor tem seu espaço, os grandes empresários destinam sua produção para o comércio nacional e internacional, enquanto os produtores de vinhos artesanais e uvas ao mercado local, beneficiando da visibilidade que a região adquire com as ações dos grandes produtores de vinhos. 
No entanto, a região também apresenta muitas dificuldades a serem superadas: a) a consolidação da região como produtora de vinhos finos no espaço brasileiro e mundial; b) o reconhecimento da Indicação de Procedência, que será uma ferramenta para o desenvolvimento da vitivinicultura regional; c) a intensificação na criação de vinícolas e infraestruturas de vinificação dentro da Campanha, pois atualmente, muitos empresários do vinho, terceirizam a vinificação. E seria importante a presença de várias vinícolas para a expansão produtiva e também para o enoturismo; d) o desenvolvimento do enoturismo através de rotas enoturísticas, pois nos dias de hoje, apenas duas rotas estão disponíveis aos turistas: a Ferradura dos Vinhedos e Rota enoturística de Bagé, (que envolve passeios nas vinícolas e pontos históricos do lugar). Estas rotas são iniciais e ainda não possuem passeios diários. A região é ampla e necessita de rotas que atinjam os vários espaços vitícolas da Campanha; e) a criação de infraestruturas para atender os turistas, tais quais: revitalização do aeroporto na região, dos pontos históricos e culturais da região, a manutenção das estradas e acessos as vinícolas, das rodoviárias e espaços públicos; f) a articulação entre hotéis, centros de cultura, restaurantes e pousadas e vinícolas para aumentar a visibilidade do vinho na região.

Contudo, a Campanha Gaúcha é uma região importante na produção de vinhos finos do Brasil no contexto contemporâneo, porém precisa se organizar para vencer as dificuldades e assim consolidar a territorialização do vinho, buscando o desenvolvimento regional (desenvolvimento este pautado na economia, sociedade e meio ambiente, valorizando o equilíbrio destas forças e a identidade regional).

A vitivinicultura mesmo sendo uma atividade exógena, ou seja, inserida por atores de fora da região, tem se constituído numa outra forma de economia. Sabe-se que a Campanha apresenta bases econômicas diferentes do restante do Rio Grande do Sul, é uma área de concentração de terras e da pecuária. Uma região que necessita de uma diversificação da agricultura e dos serviços citadinos para poder desenvolver o espaço-sociedade. A vitivinicultura representa um novo impulso para região tanto no campo com na cidade, pois esta última passa atender os turistas que se deslocam para o espaço do vinho.

As mulheres dos peões (trabalhadores da lida com a pecuária) também estão adquirindo uma nova forma de auxiliar na renda da família, pois estão trabalhando nas propriedades vitícolas na poda da videira e colheita da uva. Assim como as mulheres e filhas dos estancieiros da região estão envolvidas na gerência e na organização das atividades vitícolas, enquanto os maridos ou pais atendem os negócios da pecuária. A força feminina das empresas vitícolas nascidas na Campanha se estendeu, recentemente, para a presidência da Associação Vinhos da Campanha.

Dessa forma, a vitivinicultura traz a inserção das mulheres, das cidades, do campo entorno da diversificação dos negócios dos empresários da Campanha, assim como constitui-se num novo trabalho também para os produtores de uvas e vinhos artesanais (que não são donos de grandes extensões de terras na Campanha, mas com a uva e vinho buscam uma nova forma de renda).

\section{CONSIDERAÇÕES FINAIS}

A vitivinicultura no Rio Grande do Sul é marcada pela história da colonização e pela presença dos italianos que criaram condições para que a produção de vinhos obtivesse sucesso no espaço regional. A partir disso, o Estado Gaúcho, as instituições de pesquisa, os produtores e as próprias empresas vitícolas trilharam caminhos para que o sul fosse reconhecido pela elaboração de vinhos e pela enoturismo.

A consolidação da Serra Gaúcha como produtora de vinhos e a necessidade de novas áreas para aumentar a produção e diversificação dos produtos levou a migração de empresas para outras regiões gaúchas, especialmente Campos de Cima, Serra de Sudeste e Campanha Gaúcha.

Quanto a Campanha Gaúcha a vitivinicultura foi implantada ativamente após a década de 1970, embora os Padres Jesuítas espanhóis, nos séculos anteriores, já haviam plantado videiras neste espaço, assim como moradores locais. Atualmente, a região representa um potencial para produção de vinhos finos e para modernização vitícola, já que as condições ambientais são favoráveis. 
A vitivinicultura que se desenvolve na região é marcada por empresas da Campanha e empresas da Serra Gaúcha, além de produtores de uva e vinhos artesanais. Quanto às empresas vitícolas de fora e da região da Campanha, estas estão investindo na busca por uma Indicação de Procedência dos Vinhos da Campanha, do enoturismo e da organização do espaço para o desenvolvimento desta atividade. As empresas da Campanha buscam associar o vinho à cultura local, através da vinculação da identidade gaúcha com o vinho. Além de buscar articular uma identidade do vinho com o gaúcho e a pecuária, a fim de promover o enoturismo, ora iniciado e que movimentará mais emprego e renda aos municípios.

A Campanha Gaúcha é marcada pelas grandes e médias propriedades, onde o uso da tecnologia é possível, diferente da realidade da Serra Gaúcha, ocupada predominantemente por minifúndios e pequenas propriedades, onde as técnicas tradicionais de cuidado e trabalho nos vinhos é observada em várias propriedades.

Nesta dinâmica, a atuação da Associação Vinhos da Campanha tem sido um suporte para tecer a construção territorial do vinho e organizar o setor no âmbito regional, buscando iniciativas que conduzam o desenvolvimento da vitivinicultura. Assim como as demais associações tem sido importante para atender as necessidades dos diferentes atores territoriais do vinho.

Assim, a Campanha Gaúcha vem se tornando uma nova região promissora na produção de vinhos de qualidade. E, com isto, acontece uma reestruturação do espaço regional e das relações socioeconômicas por meio da vitivinicultura.

As mulheres são inseridas no trabalho das vinícolas, e propriedades do vinho, a cidade passa a criar novos serviços para atender a vitivinicultura, reforçando o desenvolvimento regional. Embora, a região também apresente dificuldades inerentes à inserção recente da vitivinicultura em terras de latifúndio e pecuária. Mas, sem dúvidas, com a participação dos atores, a criação de ações e estratégias coletivas pode ocorrer a consolidação da região como produtora de vinhos, sendo reconhecida mundialmente pelo dinamismo do terroir do vinho do Pampa.

A Campanha necessitava de uma nova atividade que pudesse impulsionar a região tanto socialmente quanto economicamente, como é o caso da vitivinicultura. Espera-se que os atores do território do vinho consigam superar as dificuldades e manter uma harmonia entre produtores de uva, empresas de fora da região e empresas vitícolas nascidas na Campanha, para o avanço da cadeia produtiva do vinho, a fim de aumentar a produção e gerenciarem a qualidade do vinho.

\section{AGRADECIMENTOS}

Agradecimentos à instituição de fomento a pesquisa Coordenação de Aperfeiçoamento de Pessoal de Nível Superior (CAPES), a professora orientadora da Tese de Doutorado, aos colegas de laboratório que trocaram ideias e as vinícolas e instituições entrevistadas e visitadas.

\section{REFERÊNCIAS}

COSGROVE, D. A. Geografia está em toda parte: cultura e simbolismo nas paisagens humanas. In: Corrêa, R. L.; Rosendahl, Z. (Orgs.). Paisagem, tempo e cultura. (p. 92-123). 2. ed. Rio de Janeiro (RJ): UERJ, 1998.

DAL PIZZOL, R. D.; SOUSA, S. I. de. Memórias do vinho gaúcho. Volume 1. Porto Alegre: AGE, 2014.

DUARTE, T. S.; SALAMONI, G.; COSTA, A. J. V. da. Turismo no espaço rural, práticas locais e imigração italiana: O Caminho Colonial do Vinho, Pelotas/RS. Rosa dos Ventos, Caxias do Sul, v. 3, n. 2, p. 207-215, 2011.

FALCADE, I. A paisagem como representação espacial: a paisagem vitícola como símbolo das indicações de Procedência de vinhos das regiões dos Vinhedos, Pinto Bandeira e Monte Belo 
(Brasil). 2011. 310 f. Tese (Doutorado em Geografia) - Universidade Federal do Rio Grande do Sul; Universidade de Borgonha, Porto Alegre; Dijon (França), 2011.

FARIAS, C. V. S. Redes de cooperação e internacionalização da vitivinicultura brasileira: o caso Wines From Brazil. FACEF PESQUISA, Franca, v.14, n.1, p. 52-66, jan./fev./mar./abr. 2011.

FLORES, S. S. Do Sul ao Nordeste: olhares e perspectivas sobre as novas fronteiras do vinho no Brasil. In: MEDEIROS, R. M. V.; LINDNER, M. (org.). A uva e o vinho como expressões da cultura, patrimônio e território. [recurso eletrônico]. Porto Alegre: IGEO - Instituto de Geociências, 2017, p. 125-140.

Vitivinicultura sustentável no contexto do Brasil: uma proposta de abordagem. 2015. 341f. Tese (Doutorado em Geografia) - Universidade Federal do Rio Grande do Sul. Porto Alegre: Instituto de geociências, 2015.

FLORES, S. S.; MEDEIROS, R. M. V. Ruralidades na compreensão dos territórios do vinho e sua identidade. CAMPO-TERRITÓRIO: revista de geografia agrária, v. 8, n. 15, p. 1-19, fev. 2013.

JALFIM, A.; GRANDO, M. Z. Os novos rumos da vitivinicultura no RS. Indicadores econômicos FEE, Porto Alegre, v. 17, n. 4, p. 194-206, 1990.

MANFIO, V. Vitivinicultura e associativismo: a dinâmica da Associação Vinhos da Campanha na formação de um território no Rio Grande do Sul, Brasil. 260f. 2018. Porto Alegre. Tese (Doutorado em Geografia) - Universidade Federal do Rio Grande do Sul. Porto Alegre, 2018.

MANFIO, V.; MEDEIROS, R. M. V.; FONTOURA, L. F. M. Repensando as relações campo/cidade: uma abordagem acerca do terroir do vinho na Campanha Gaúcha. CAMPO-TERRITÓRIO: revista de geografia agrária, v. 11, n. 22, p. 222-242, abr. 2016.

MANFIO, V.; MEDEIROS, R. M. V. A territorialização da vitivinicultura na Campanha Gaúcha e o monopólio das grandes vinícolas. In: I Congresso Internacional do Pampa e III Seminário de Sustentabilidade da Região da Campanha. Santa Maria, 2016. Anais... Santa Maria: UFSM, 2016. https://doi.org/10.14393/RCT112209

A vitivinicultura e as novas territorialidades na Campanha Gaúcha: um território em construção. Geoingá: Revista do Programa de Pós-Graduação em Geografia Maringá, Maringá, v. 9, n. 2, p. 136-155, 2017.

MATTEI, L.; TRICHES, V. Análise da Competitividade da Cadeia Vitivinícola do Rio Grande do Sul através do Ambiente Institucional. Análise Econômica, Porto Alegre, ano 27, n. 52, p. 161-183, set. 2009.

MELLO, L. M. R. de; MACHADO, C. A. E. (Editores técnicos). Cadastro Vitícola do Rio Grande do Sul: 2013 a 2015. Brasília - DF: Embrapa, 2017.

NIEDERLE, P. Compromissos para a qualidade: projetos de indicação geográfica para vinhos no Brasil e na França. 2011. 263 f. Tese (Doutorado em Ciências Sociais) Universidade Federal Rural do Rio de Janeiro, Instituto de Ciências Humanas e Sociais. Rio de Janeiro, 2011.

NIEDERLE, P. AGUIAR, M. INDICAÇÕES GEOGRÁFICAS, TIPICIDADE E PRODUTOS LOCALIZADOS: os novos compromissos valorativos na vitivinicultura do Vale dos Vinhedos. Revista de Economia Agrícola, São Paulo, v. 59, n. 2, p. 21-37, jul./dez. 2012.

OLIVEIRA, J. da S.; MARTINEZ, J. F.; SANTOS, L. R. S. dos. Enoturismo na região da Campanha Gaúcha. Revista Brasileira de Viticultura e Enologia. n. 7, p.118-124, 2015.

ORTEGA, A. C.; JEZIORNY, D. L. Vinho e território: a experiência do Vale dos Vinhedos. Campinas - SP: Alínea, 2011.

PIEROZAN, V. L.; MANFIO, V.; MEDEIROS, R. M. V. Vitivinicultura orgânica no Rio Grande do Sul: a expansão da produção sustentável de uva, vinho e suco em Cotiporã e Dom Pedrito. p. 26182631. In: XXIV Encontro Nacional de Geografia Agrária. 2018. Dourados-MS. Anais... DouradosMS, 2018. https://doi.org/10.22533/at.ed.2001915048

REAL, M. C. Os bons vinhos do Sul. Porto Alegre: Sulina, 1981. 
SALVAGNI, J.; VALDUGA, V.; NODARI, C. H. Cooperação como propulsora da inovação em turismo na Região Uva e Vinho do Rio Grande do Sul, Brasil. Outra Economía, São Leopoldo: UNISINOS, v. 10, n.19, p. 253-262, jul-dez 2016. https://doi.org/10.4013/otra.2016.1019.11

SANTOS, J. V. T. dos. Colonos do vinho: estudos sobre a subordinação do trabalho camponês ao capital. São Paulo: Hucitec, 1978.

SILVA, L.F.M. De celeiro a cenário: vitivinicultura e turismo na Serra Gaúcha. GEOUSP - Espaço e Tempo, São Paulo, Edição Especial, p. 107 - 125, 2009. https://doi.org/10.11606/issn.21790892.geousp.2009.74145

SILVA, F. N. da; ANJOS, F. S. dos; SILVEIRA, D. F. da. Ressignificação identitária: o caso da vitivinicultura na região da Campanha Gaúcha, Rio Grande do Sul, Brasil. Revista THEOMAl, n. 38, p. 186-206, 2018.

SOUSA, J. S. I. de. Uvas para o Brasil. São Paulo: Melhoramentos, 1969.

TONIETTO, J. Vinhos brasileiros de 4ª geração: o Brasil na era das indicações geográficas.

Comunicado técnico, n.45. Bento Gonçalves/RS: Embrapa: 2003.

VALDUGA, V. Raízes do turismo no território do vinho Bento Gonçalves e Garibaldi - 1870 a 1960 (RS - Brasil). 2011. 219 f. Tese (Doutorado em Geografia) - Universidade Federal do Rio Grande do Sul. Porto Alegre, 2011.

ZERO HORA. Expansão e novidades para conquistar muitos públicos. Caderno Especial: Vinhos \& Espumantes. Porto Alegre, 24 de nov. 2017.

Recebido em: 08/08/2018

Aceito para publicação em: 13/06/2019 